\title{
Disentangling ecosystem engineering from short-term biotic effects of a strong invader on a native foundation species
}

\author{
Proença Barbara ${ }^{1,}{ }^{*}$, Romuald Marine ${ }^{1}$, Auby Isabelle ${ }^{2}$, Ganthy Florian ${ }^{2}$, Sottolichio Aldo ${ }^{1}$, \\ Michalet Richard ${ }^{1}$
}

1 University of Bordeaux, U.M.R. 5805 EPOC, 33405 Talence cedex, France

2 IFREMER Arcachon, 33120 Arcachon, France

*Corresponding author : Barbara Proença, email address : barbara.proenca@u-bordeaux.fr

\begin{abstract}
:
Ecosystem engineering effects of dominant species on habitats and consequently on other species are likely to propagate through time at longer distance than the close neighbourhood. Such effects are important to disentangle from short-term biotic effects, especially in biological invasions, as engineering can explain changes in invasion rates over the course of the invasion. We assessed the contribution and spatial dynamics of ecosystem engineering effects of a strong invader, the cordgrass Spartina anglica, on Zostera noltei, a foundation seagrass species of muddy intertidal systems in Europe. Z. noltei transplants were grown at different positions along transects crossing intact $S$. anglica patches, cut patches and nearby bare sediment on tidal flats in the Bay of Arcachon (France), in order to separate ecosystem engineering effects from short-term biotic effects and evaluate their likely spatial propagation. Bed altimetry, sediment redox potential and granulometry were measured in all treatments. Within Spartina patches, we found strong negative ecosystem engineering effects of the cordgrass on the seagrass associated with increased sediment elevation and relative fine sediment content. Up to $2 \mathrm{~m}$ outside the patch, we found significant negative ecosystem engineering effects and positive short-term biotic effects, but they were weak and counterbalanced each other. We conclude that $S$. anglica can transform a marine muddy intertidal habitat into a drier and more oxidized terrestrial habitat, no longer suitable for the seagrass. Although these effects may propagate at several metres from a patch, they appeared to be too weak to likely affect the seagrass at the scale of a whole bay.
\end{abstract}

Keywords : Biological invasion, Competition, Ecosystem engineer, Spartina anglica, Zostera noltei 


\section{Introduction}

Biological invasion is a highly dynamic process, both in time and space (Pyšek \& Hulme 2005, Mitchell et al. 2006, Theoharides \& Dukes 2007). The impact of an invasive species may vary over the course of the invasion, with invasion rates changing through different ecological and evolutionary processes that may increase or attenuate the impact of invaders on the resident community (Strayer et al. 2006). Indeed, species' evolution has been shown to be an important driver of invasion accelerations, as shown for several plant species after hybridization and polyploidy events (Baumel et al. 2001, Ainouche et al. 2009, Treier et al. 2009, te Beest et al. 2012). For example, the cordgrass Spartina anglica became a strong invader in European salt marshes after hybridization in UK between the North-American species Spartina alterniflora and the native Spartina maritima, followed by a polyploidy evolution (Baumel et al. 2001, Strong \& Ayres 2013). In contrast, a decrease in invasion success may arise from plant-soil feedback processes (Dostál et al. 2013) or decrease in allelopathic compounds of the invader through time (Lankau et al. 2009).

Changes in invasion rates related to population and community dynamics can be fast, in contrast to ecosystem-driven invasion changes that might need a much longer time to occur, in particular when soil weathering processes are involved (Vilà et al. 2011, Strayer 2012). In coastal systems, several species have been shown to strongly enhance their invasion rate due to their high ecosystem engineering abilities (Crooks 2002, Zarnetske et al. 2012). Ecosystem engineers contribute to shaping the space they colonize by interacting with incident physical forces like wind in sand dune systems (Seabloom et al. 2013) and currents and waves in marine systems (Bouma et al. 2005, 2007, Paul \& Gillis 2015) and, hence, inducing long-term changes in landscape morphology and physical habitats (Balke et al. 2012). One important challenge in biological invasion studies' is to disentangle short-term 
biotic processes, mainly related to the effects of vegetation on resources, from ecosystem engineering processes, associated to soil or sediment modification, in order to improve our understanding of the temporal and spatial dynamics of biological invasions and their effects on biological diversity, ecosystem functioning and ecosystem services. This is particularly the case for cordgrasses invasion in salt marshes, known to involve both evolutionary and ecosystem changes (Baumel et al. 2001, Bouma et al. 2005, Ainouche et al. 2012, Strong \& Ayres 2013).

Disentangling ecosystem-engineering from short-term biotic effects is feasible using specific methodologies, as already applied in terrestrial systems (Michalet 2006, Schöb et al. 2012, Michalet et al. 2015, 2017, Noumi et al. 2015, 2016), but not yet tested in coastal systems. This method can only be used in stressed and/or highly disturbed systems where vegetation cover is not continuous, with patches of vegetation alternating with patches of bare ground. The short-term biotic effects of a living neighbour on resources (light, water and nutrient), disturbance and microclimate are quantified by comparing the performance of a first plant individual growing within the canopy of the living neighbour to that of a second individual growing in an area where neighbours have been removed. The ecosystemengineering effects of the neighbours are quantified by comparing the performance of a third individual growing in naturally open patches to that of the second individual growing in removed-vegetation. This quantifies the legacy effects over several generations of the neighbours on soil characteristics, and in particular positive effects on nutrient, water retention, but also interference effects due to litter accumulation (Michalet et al. 2017). Finally, the comparison of the performance of the first and third individuals quantifies the sum of the short-term biotic and ecosystem-engineering effects of the neighbour, i.e. its net effects on the target plant. This method has proven efficient in separating these two effects but 
can only be used in communities where within-habitat environmental heterogeneity is due to ecosystem engineering effects. Indeed, the results can be confounded by pre-existing environmental heterogeneity, as likely occurring in many mountainous systems at the meterscale (see Steinbauer et al. 2016). In contrast, such confounding effects are less likely to occur at this scale in muddy intertidal systems where within-habitat environmental heterogeneity is low and, thus, mostly existing when induced by ecosystem engineering effects (Bouma 2009).

One interesting aspect of the ecosystem engineering effects on landscape dynamics and biological invasions compared to short-term biotic effects is their likely extension to larger spatial scales than the closest neighbours (Rietkerk \& van de Koppel 2008, Vu et al. 2017). One example are the dune-forming species in coastal systems, where their sandtrapping effects can have landscape consequences on dune height and morphology and, ultimately, control storm-wave overtopping, as shown by Zarnetske et al. (2012) and Seabloom et al. (2013) along the North-American Pacific coast (Oregon, USA). Similarly, Bouma et al. (2005) have suggested that the invasive Spartina anglica may negatively affect Zostera noltei in Dutch tidal flats through sediment trapping, likely to affect neighbouring habitats at several meters beyond their canopy. These species' effects at large scale are important to consider in biological invasions since they may explain changes in invasion rates in natural landscapes. However, their assessment needs specific methodologies that, to our knowledge, have never been applied nor implemented.

In coastal intertidal systems, saltmarshes and mudflats are vulnerable habitats characterized by a high susceptibility to biological invasions (Hacker et al. 2001). The importance of natural and anthropogenic physical disturbances facilitates the colonization by invasive species, as shown in riparian systems (Planty-Tabacchi et al. 1996, Saccone, Brun, et al. 2010, Saccone, Pagès, et al. 2010). Studies in intertidal coastal systems have highlighted 
the importance of interactions between plants or other sessile organisms in enhancing native diversity or favouring biological invasions (Bertness \& Ewanchuk 2002, Bruno et al. 2003, Altieri et al. 2010). Natural ecosystem vulnerability is even higher when invaders are also strong ecosystem engineers (Vitousek 1990, Crooks 2002). We assessed here the responses of the native foundation species of intertidal mudflats, Zostera noltei to the ecosystem engineering and short-term biotic effects of the strong invasive ecosystem engineer of European salt marshes, Spartina anglica. There is a current important concern about the global decline of Zostera beds (Orth et al. 2006, Waycott et al. 2009), due to the crucial role of Zostera species as foundation species of coastal intertidal systems (Duarte 2002). Several reports of decaying Zostera beds have been documented, in the Wadden Sea, Netherlands (Den Hartog \& Polderman 1975), in the Bay of Arcachon, France (Plus et al. 2010), in the Mira estuary, Portugal (Branco et al. 2017) or in the Chesapeake Bay, USA (Lefcheck et al. 2017). Although the influence of anthropogenic factors in this decline has been suggested (Orth et al. 2006, Waycott et al. 2009), the exact causes are still not fully understood. In France (Boudouresque et al. 2009), and in particular in the Bay of Arcachon (Plus et al. 2010), it has been hypothesized that it could be related to a combination of factors, which includes extreme temperature events (Massa et al. 2009) and decrease in light availability due to increasing sediment content in the water column (van der Heide et al. 2010, Suykerbuyk, Bouma, et al. 2016, Lefcheck et al. 2017). Recently, Cognat et al. (2018) have shown that the performance of Zostera noltei in the Bay of Arcachon was primarily controlled by the hydrodynamics and secondarily by light availability. Although there has been some experimental studies on interactions between Zostera species (Bando 2006, Gribben et al. 2009), to our knowledge, no studies have directly assessed the interactions between seagrasses and marsh species using removal procedures. 
In the Bay of Arcachon the decline of Z. noltei meadows has been first reported in the early 2000s and its dynamics documented during the last 20 years (Auby \& Labourg 1996, Plus et al. 2010). Specifically, Plus et al. (2010) calculated a 33\% decline in surface between 1989 and 2007. Interestingly, this decline occurred, approximately 10-15 years after the introduction and expansion peak of S. anglica (Le Nindre et al. 2004). Considering the high sensitivity of Z. noltei to light conditions, the decrease in light availability associated to sediment dynamics (Suykerbuyk, Bouma et al. 2016, Suykerbuyk, Govers, et al. 2016) and the well-known role of $S$. anglica as ecosystem engineer through sediment trapping (Bouma et al. 2005, 2007), it can be hypothesized that the contingency of the recent dynamics of the two species in the Bay of Arcachon could be explained by causal relationships. The ecosystem engineering effect of $S$. anglica may be sufficiently strong to modify the environment in a negative way for the seagrass beds. As suggested by Bouma et al. (2005) the stiff stems of the cordgrass may affect waves and currents promoting accretion and bed elevation to levels offering too much drought stress for the seagrass. However, and in order to ultimately consider the contribution of the cordgrass to the decline of the seagrass, we first need to assess if the cordgrass can negatively affect the seagrass through ecosystem engineering effects and at least at longer distance than the patch scale. Thus, we aim to answer two main questions:

(i) Does S. anglica affect Z. noltei through either ecosystem engineering or short-term biotic processes?

(ii) Do S. anglica effects on Z. noltei extend to larger spatial scales than the immediate neighbour level? 


\section{Materials and methods}

\subsection{Study site and species}

Our experiment was conducted in the eastern part of the Bay of Arcachon, a mesotidal lagoon system (tidal range: 0.8-4.6 m), located along the Aquitaine Atlantic coast, in the southwest of France $\left(44^{\circ} 43 \mathrm{~N}, 1^{\circ} 04 \mathrm{~W}-\right.$ Figure 1a). The introduction of Spartina anglica in this lagoon dates from the mid-eighties (Laporte-Cru \& Werno 1989). The origin of this invasive species begins with the hybridization between $S$. alterniflora (native from the USA) and S. maritima, another cordgrass species native from Europe. This event occurred in the UK and gave birth, first to a sterile hybrid and, then, to the fertile new species $S$. anglica through polyploidy evolution (Raybould et al. 1991, Baumel et al. 2001). S. anglica forms diffuse thick stems with large and stiff leaves and a very dense rhizome system. This species occurs not only close to the land, like the native $S$. maritima, but also in small patches throughout the tidal flat. Z. noltei is an intertidal seagrass species that presents a high sensitivity to physical disturbances. While the decline of $Z$. noltei meadows was first noticed in the Wadden Sea in the 1960s, it was not until the 2000s that this species' meadows started to be affected in the Bay of Arcachon (Plus et al. 2010).

\subsection{Experimental design}

In order to assess the ecosystem engineering and short-term biotic effects of Spartina anglica on Zostera noltei's performance, (first question) and the spatial extent of these effects (second question), we conducted, between the $21^{\text {st }}$ January $\left(T_{i}\right)$ and $20^{\text {th }}$ May $\left(T_{f}\right) 2016$, a field experiment where we transplanted Z. noltei in three conditions of S. anglica's influence (without Spartina, within intact-Spartina and within cut -Spartina) and at different distances 
from Spartina's influence (Figure 2). We first randomly selected as treatment replicates four patches of $S$. anglica of approximately 40 to $50 \mathrm{~m}^{2}$. We considered isolated, elliptical $S$. anglica tussocks and within each tussock we delineated two parallel transects to the length of the tussock for the transect treatment, with at least 5 meters between transects within a single patch. All transects were oriented in the direction of the predominant wave incidence, i.e. perpendicularly to the shore. We randomly selected one half of the patch to apply the cutSpartina treatment (SAC) and removed with scissors all aboveground parts of S. anglica (the only plant species present in the patch) within a distance of two meters from the transect, on each side of it. The cut vegetation was withdrawn from the site and the removal was conducted twice during the experiment due to the regrowth of $S$. anglica. The vegetation was left intact in the other transect for the intact-Spartina treatment (SA). For each replicate, we also delineated in the bare sediment nearby a third transect at a minimum of 10 meters away from the patch, for the control treatment. In each of the $3 \times 4$ transects, we selected for the position treatment eight positions along the transect where we transplanted Z. noltei: two on the offshore side of the patch, at $1 \mathrm{~m}$ and $0.5 \mathrm{~m}$ from the limit of the $S$. anglica patch respectively, three inside the patch (one at the centre and the two others at $0.5 \mathrm{~m}$ from the offshore and onshore edges of the S. anglica patch, respectively) and three on the onshore side of the $S$. anglica patch at $0.5 \mathrm{~m}, 1 \mathrm{~m}$ and $5 \mathrm{~m}$ away from the patch. We collected all $Z$. noltei transplants in the vicinity of the patches using a metal box of $12.5 \times 8.5 \times 8 \mathrm{~cm}$ dimensions inserted within the muddy sediment. Each transplanted plot included six to twelve Z. noltei individuals. All transplanted plots were inserted at the eight positions of the twelve transects making, thus, a total of 96 transplanted plots. The transects had varying lengths across replicates, but the distances between positions within replicates were kept constant to allow a comparison between the cut-transects, intact-transects and control transects. Each transplanted plot was delimited with wooden sticks located on the corners of the transplant 
surface to enable their identification during site inspections. Non-transplanted Z. noltei performance transects were also designed in order to control for the effects of transplantation. No significant effects associated with transplanting methodology were found.

\subsection{Monitoring of Zostera noltei performance and environmental measurements}

Shoot density $(D)$ and the length of the longest leaf $(L)$ of Zostera noltei were measured at $\mathrm{T}_{\mathrm{i}}$ and $\mathrm{T}_{\mathrm{f}}$ for all transplanted plots. We then calculated $Z$. noltei growth rates $(\mu)$ between the initial $\left(\mathrm{T}_{\mathrm{i}}\right)$ and final times $\left(\mathrm{T}_{\mathrm{f}}\right)$ of the experiment using equation 1 , were $\mathrm{X}$ corresponds to $D$ or $L$, respectively.

$\mu=\left(\mathrm{X}_{\mathrm{Tf}}-\mathrm{X}_{\mathrm{Ti}}\right) / \mathrm{X}_{\mathrm{Ti}} \quad$ eqn 1

At each transect position and for all transects, elevation measurements were made at the centimetre precision with a RTK Leica GS10 system and surface sediment samples were collected in order to perform grain size analysis. Redox potential was measured with an Ehmeter probe assembled in a multi-parameter box (PofiLine Multi 3320). The analysis of the sediment of overall samples revealed that the sediment was mainly composed of sand and silt, with very low percentage of clay $(<5 \%)$. To simplify the analysis of sediment characterisation, silt and clay percentages were merged into one category, in order to provide a quantification of fine (cohesive) vs. sandy (granular non-cohesive) sediment content. 


\subsection{Plant-plant interaction indices}

To investigate the effects of Spartina anglica on Zostera noltei performances in the transplanted plots we used the Relative Interaction Index of Armas et al. (2004):

$\mathrm{RII}=\left(\mathrm{X}_{\text {with neighbour }}-\mathrm{X}_{\text {without neighbour }}\right) /\left(\mathrm{X}_{\text {with neighbour }}+\mathrm{X}_{\text {without neighbour }}\right) \quad$ eqn 2

where $\mathrm{X}$ corresponds to the performances $(D$ or $L)$ of $Z$. noltei in the transplanted plots.

This index varies between -1 and 1 . Negative values indicate a negative effect (competition), positive values a positive effect (facilitation) and zero value corresponds to no significant interaction.

Three RIIs were calculated in order to separate the ecosystem engineering and shortterm biotic effects of Spartina anglica on Z. noltei, following Michalet et al. $(2015,2017)$.

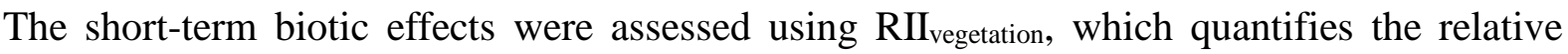
difference in performance between Z. noltei transplants growing in intact-Spartina transects vs. cut-Spartina transects (actual effect of living S. anglica individuals on Z. noltei, through changes in resources, disturbance, space and microclimate), whereas the ecosystem engineering effects were assessed using $\mathrm{RII}_{\text {soil, }}$, which quantifies the relative difference in performance of Z. noltei transplants growing in cut-Spartina transects vs. control transects (long-term effects of S. anglica on Z. noltei, through legacy effects on environmental conditions within the sediment, i.e. changes in sediment elevation, texture, nutrient content). Finally, RII Spartina quantifies the total effects of S. anglica on Z. noltei performance, i.e., the sum of the two previous effects, through the estimation of the relative difference in performance of $Z$. noltei transplants growing in intact-Spartina transects vs. control transects. The description of the variables considered in each RII is summarized in Table 1. 


\subsection{Statistical analysis}

We analysed the effects of the transect (SA, SAC and control), position treatments and their interaction on the logarithm of final abundance of Z. noltei with a split-plot analysis of covariance (split-plot ANCOVA), with transect as main effect and position as sub-effect. We also used a split-plot ANCOVA to analyse the effects of the method (to quantify short-term biotic and ecosystem engineering effects of $S$. anglica), position treatments and their interaction on RII final abundance of Z. noltei, with method as main effect and position as sub-effect. In both split-plot ANCOVAS we used both a linear and quadratic term of the position effect in order to eventually detect non-linear relationships. The best model was chosen by application of a stepwise method using the AIC criterion (Akaike 1973). We also used one-way ANOVA to assess the effects of the transect or method effects at each position along transects. To simplify the representation of the results we pooled the two upstream positions into one upstream point ( $\left.\mathrm{P}_{\text {offshore }}\right)$, the three positions within the patch into one patch position $\left(\mathrm{P}_{\text {patch }}\right)$ and the two first downstream positions into a first downstream point $\left(\mathrm{P}_{\text {onshore1 }}\right)$. We used one sample t-tests to assess significant deviations of RII means from zero values. For environmental data (altimetry, redox potential and relative fine sediment content), we used a three-way ANCOVA to test effects of transect, position and position ${ }^{2}$ and their interactions. We also used one-way ANOVAs to assess the effect of the transect treatment at each position. For all analyses we also conducted post-hoc Tukey HSD tests when necessary. Data normality was verified through a Shapiro-Wilk test (Shapiro \& Wilk, 1965), for which we obtained $\mathrm{W}=0.916(\mathrm{p}<0.001)$ on final Zostera noltei abundance and $\mathrm{W}=0.934(\mathrm{p}<$ 0.001) on RII. Because data met the normality criterium (values of W close to 1), no transformations were applied. All statistical analyses were performed with $\mathrm{R}$ version 3.3.2 ( $\mathrm{R}$ Development Core Team 2013). 


\section{Results}

There was a highly significant transect effect in the ANCOVA on Zostera noltei abundance $\left(\mathrm{F}_{2,87}=12.96, \mathrm{p}<0.001\right.$, Table 2$)$, because, over all positions along the transects, the abundance of Z. noltei was higher in the control transects (without Spartina) than in the cutSpartina transects, with intermediate values for the intact-Spartina transects (Figure 3, Tukey, intact-Spartina (A), cut-Spartina (A), control (B)). We also found a highly significant effect of the position ${ }^{2}$ treatment $\left(\mathrm{F}_{1,87}=19.55, \mathrm{p}<0.001\right.$, Table 2$)$ because, overall transects, $Z$. noltei abundance was much lower at the $\mathrm{P}_{\text {patch }}$ position than at the other three positions (Figure 3, Tukey, $\mathrm{p}<0.05$ ). However, there was a significant treatment $\mathrm{X}$ position ${ }^{2}$ interaction, because this quadratic position effect was only observed for the cut-Spartina and intact-Spartina transects $\left(\mathrm{F}_{2,87}=5.42, \mathrm{p}=0.006\right.$, Table 2$)$. Indeed, at the $\mathrm{P}_{\text {patch }}$ position $\mathrm{Z}$. noltei abundance was close to 0 in both the SA and SAC transects vs. $24( \pm 3.15)$ individuals on average in the control transects. In contrast, at the $\mathrm{P}_{\text {onshore }}$ position $\mathrm{Z}$. noltei abundance was $50 \%$ lower $(16.6 \pm 6.35$ individuals $)$ in the cut-Spartina than in the intact-Spartina transects ( $32 \pm 5.7$ individuals) and there were no significant differences among treatments at the other two positions.

There was a highly significant method effect $\left(\mathrm{F}_{2,87}=23.59, \mathrm{p}<0.001\right.$, Table 2$)$ in the ANCOVA on RIIs abundance because, overall positions, both RII $_{\text {soil }}$ and RII Spartina $_{\text {values }}$ were globally negative, whereas $\mathrm{RII}_{\text {vegetation }}$ values were slightly positive (Figure 4, Tukey, $\left.\mathrm{RII}_{\text {soil }}(\mathrm{B}), \mathrm{RII}_{\text {vegetation }}(\mathrm{A}), \mathrm{RII}_{\text {Spartina }}(\mathrm{B})\right)$. There was also a significant position ${ }^{2}$ effect $\left(\mathrm{F}_{1,87}=\right.$ 11.46, $\mathrm{p}=0.001$, Table 2) because, overall RII types, RIIs abundance values were lower (and negative) at the $\mathrm{P}_{\text {patch }}$ position than at the other three positions. However, there was a 
marginally significant method $\mathrm{x}$ position ${ }^{2}$ interaction $\left(\mathrm{F}_{2,87}=2.73, \mathrm{p}=0.071\right.$, Table 2$)$ because the very negative RII values at the $\mathrm{P}_{\text {patch }}$ position were only observed for $\mathrm{RII}_{\text {soil }}$ and

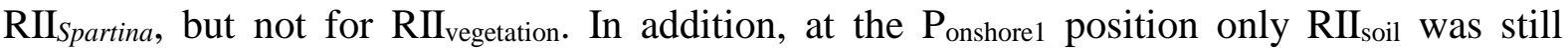
significantly negative, whereas $\mathrm{RII}_{\text {Spartina }}$ was null and RII vegetation even significantly positive. Overall, these results show that $S$. anglica had dominant negative soil effects and that, although these effects were by far the strongest within the Spartina patch, they slightly extended at least up to $5 \mathrm{~m}$ downstream from the Spartina patch (position $\mathrm{P}_{\text {onshore2) }}$ and even up to $1 \mathrm{~m}$ upstream (significant sample t-tests at all positions along transects for $\mathrm{RII}_{\text {soil }}$ ).

There was a significant transect effect $\left(\mathrm{F}_{2,103}=4.42, \mathrm{p}=0.014\right)$ in the ANCOVA conducted on elevation because, overall positions, elevation was lower in the control transects than in both intact-Spartina and cut-Spartina transects (Figure 5a). There was also a significant position ${ }^{2}$ effect $\left(\mathrm{F}_{1,103}=8.17, \mathrm{p}=0.005\right)$ because, overall transects, elevation was higher at the level of the Spartina patches (positions 3 to 5) than at all other positions. Finally, there was a weakly significant transect $\mathrm{X}$ position ${ }^{2}$ interaction $(\mathrm{F} 2,103=3.95, \mathrm{p}=0.022)$, because the higher elevations observed at the levels of the Spartina patches occurred only in the SA and SAC transects but not in the control transects, and in particular at P4, the position at the centre of the patch (see result of the one-way ANOVA at P4: p < 0.001; Tukey, SA (a), SAC (a), control (b)).

We found a marginally significant interaction between the transect and position treatments $\left(\mathrm{F}_{2,103}=2.96, \mathrm{p}=0.056\right)$ in the ANCOVA conducted on soil redox potential because redox potential was overall higher in the intact-Spartina than in the cut-Spartina transects on the offshore side of the patch and in the Spartina patch, whereas the opposite was observed on the onshore side of the patch. In particular, at position 4 (centre of the patch) redox potential was significantly lower in the cut-Spartina transects than in the other two 
transect types (one-way ANOVA $F_{2,11}=7.71, \mathrm{p}=0.008$ Figure 5b; Tukey, intact-Spartina (a), cut-Spartina (b), control (a)).

There was a significant position effect $\left(\mathrm{F}_{1,103}=10.81, \mathrm{p}=0.001<0.01\right)$ in the ANCOVA conducted on relative fine sediment content because, overall transects, points from the level of the Spartina patches and upstream the patches had lower fine sediment content than points downstream the patches and in particular position 2 vs position 5 , respectively (Figure 5b, Tukey, $\mathrm{p}<0.01$ ). There was also a marginally significant position $\mathrm{X}$ transect interaction $\left(\mathrm{F}_{2,103}=2.66, \mathrm{p}=0.074\right.$, Table 3$)$, because these differences in relative fine sediment content across positions were only found for the SA and SAC transects but not for the control transects and in particular for position P5 (one-way ANOVA at P5: $F_{2,11}=10.61, p$ =0.003; Tukey, SA (a), SAC (a), control (b)).

\section{Discussion}

At short distance (i.e. within Spartina patches), we found dominant negative ecosystem engineering effects of $S$. anglica on $Z$. noltei that were correlated with two long-term environmental modifications, an increase in elevation and in relative fine sediment content. This was also correlated to an increase in sediment oxygenation, but not to any positive shortterm effect for the seagrass. At long distance, effects on Z. noltei were much weaker, but negative ecosystem engineering effects on environmental conditions were still significant up to two meters downstream the Spartina patch, while weak significant positive short-term biotic effects were observed until one meter downstream the Spartina patch. These results provide evidence that a strong invader of salt marshes can negatively affect an important foundation seagrass species of intertidal mud flats, mostly through ecosystem engineering effects occurring at short distance. 


\subsection{The short-distance effects of Spartina anglica on environmental conditions and Zostera noltei}

The role of Spartina species as ecosystem engineers of muddy intertidal systems has been widely documented (Crooks 2002, Bouma et al. 2005, Strong \& Ayres 2013). In tidal flats they interact with the hydrodynamic forces in a way that promotes significant bed level elevation, commonly forming dome shaped tussocks or small islands, and ultimately salt marshes (Balke et al. 2012). The specific ability of $S$. anglica to trap sediment and to behave as an ecosystem engineer that expands its habitat by enhancing sediment accretion has been widely acknowledged (Castellanos et al. 1994, Sánchez et al. 2001, Bouma et al. 2005). Bouma et al. (2005) have shown that $S$. anglica was able to modify its physical environment by reducing hydrodynamic energy from waves with its stiff stems, at the cost of relatively large drag forces. In our study, we showed, through dGPS elevation measurements in the tidal flat, that Spartina meadows were associated with significant higher bed level than surrounding Z. noltei habitats. Contrasting elevations were associated to higher relative fine sediment content for the Spartina patches, since both habitat modifications were induced by the higher sediment-trapping ability of S. anglica as compared to Z. noltei (Bouma et al. 2005). These parallel changes in habitats conditions and random distribution of Spartina patches on the tidal flats (B. Proença personal observation) strongly suggest that differences in elevation between S. anglica and Z. noltei habitats cannot be due to pre-existing environmental heterogeneity that could have confounded our results, as likely to occur in terrestrial habitats where within-habitat environmental heterogeneity is much higher than in muddy intertidal systems (Steinbauer et al. 2016). Additionally, our measurements of annual sediment deposition below Spartina canopies in the Arcachon Bay show that the observed 
difference in elevation between Spartina patches and adjacent bare tidal flat are achieved in time scales of the order of decades (Proença et al. in preparation).

Given the low performance of Zostera noltei transplants within the cordgrass patches', the sediment-trapping activity of $S$. anglica can gradually transform this marine habitat to a system that no longer can be inhabited by Z. noltei, as already suggested by Bouma (2009). Several studies have shown the sensitivity of seagrasses to desiccation stress (van der Heide et al. 2010, Kim et al. 2016, Suykerbuy, Govers, et al. 2016) and, even though Z. noltei possesses physiological adaptations to reduce tissue water loss and keep appropriate photosynthesis levels during emersion periods (Larkum et al. 2006, Folmer et al. 2016), desiccation stress might still be a limit to its colonization of higher intertidal levels (van der Heide et al. 2010, Folmer et al. 2016). Additionally, in higher exposed bed levels, Z. noltei is submitted to longer and wider range of temperature changes, another relevant factor for the seagrass performance (Marba et al. 1996).

Using a specific methodology that was already applied in terrestrial systems, we were able to disentangle ecosystem engineering legacy from short-term biotic effects and to demonstrate that only the former could explain the competitive exclusion of $Z$. noltei by $S$. anglica, thus supporting this assumption of previous authors. At short distance (within Spartina patches), we showed that $S$. anglica had no significant short-term biotic effects for Z. noltei. S. anglica had a significant short-term biotic effect on habitat conditions, in particular strongly enhancing sediment oxygenation. Although higher sediment oxygenation due to the effects of ecosystem engineers is known to positively affect many salt marsh species (Callaway \& King 1996, Hacker \& Bertness 1999), this did not positively affect $Z$. noltei, likely because this is an aquatic species adapted to anoxia but not to drought. Additionally, a likely benefit of increased oxygenation might have been outweighed by the 
cost of drought. It should be noticed that the competitive exclusion of $Z$. noltei due to drought stress induced by S. anglica, could not be considered as an example of resource competition related to the high ability of $S$. anglica to uptake water, but it is a consequence of a long-term ecosystem engineering effect of the invasive. Thus, this is rather an example of interference effect on water sediment content due to legacy effects of ecosystem engineers on habitat conditions, as already shown in terrestrial alpine systems where the accumulation of hydrophobic litter through time may induce a water stress for other species (Michalet et al. 2017).

\subsection{The long-distance effects of Spartina anglica on environmental conditions and Zostera noltei}

Although much weaker than within Spartina patches, negative ecosystem engineering effects were still present outside the patch, because $\mathrm{RII}_{\text {soil }}$ values were significantly negative at all points of the transects. Downstream the patch this was correlated with a tendency for higher relative fine sediment content for intact-Spartina transects than for the control transects, whereas it was the converse upstream the patch where relative fine sediment content of the control transects tended to be higher than those of the other two transect types (significant interaction between the transect and position treatments). This suggests that the negative ecosystem engineering effects on Z. noltei occurring downstream the patch were still due to the sediment-trapping effect of $S$. anglica. This shows that these effects may negatively affect seagrass beds located at several meters from the invasive species, as suggested by Bouma (2009). In contrast, the negative ecosystem engineering effects occurring on the offshore side of the Spartina patches were likely due to increased wave energy and, thus, physical disturbance for the seagrass at the front of the patch. Ganthy et al. (2013) also showed for $Z$. 
noltei beds that an increase in wave action during energetic winter events favours superficial fine sediment erosion thus inducing a coarser sediment texture. In contrast, they found higher fine sediment content under lower energy incidence.

Remarkably, we found positive short-term biotic effects of S. anglica on Z. noltei at a distance of one meter downstream the patch. This shows that the canopy of the cordgrass facilitated the seagrass, just downstream the Spartina patch, likely through a reduction of the hydrodynamic energy by the stiff stems of the cordgrass (Bouma et al. 2005). Again, considering sediment properties as a proxy to the hydrodynamic conditions, our sediment measurements along the transects are consistent with an effective energy reduction by the Spartina vegetation and a protective effect downstream the Spartina patches In our experiment, for Z. noltei, at the points under the shelter effect of $S$. anglica, both the reduction of incident energy and the associated more stable sediment conditions likely decreased physical disturbance, thus, slightly ameliorating the habitat for a suitable development of the seagrass (Folmer et al. 2016, Suykerbuyk, Bouma, et al. 2016, Suykerbuyk, Govers, et al. 2016). However, for Paul \& Gillis (2015), a minimum level of wave and current action is certainly needed for the seagrass since the physical remobilization of the leaves, especially in dense meadows can decrease self-shading and increase nutrient uptake.

However, all these subtle negative or positive legacy or short-term effects observed outside of the Spartina patches, up to a distance of two meters from the patches, counterbalanced each other since all net effects measured outside the patch were not significant. Thus, although further experiments including longer transects with more replicates and located in varying conditions of hydrodynamics are certainly needed, our results strongly suggest that the long-distance effects of S. anglica are too weak to potentially 
contribute to the decline of Z. noltei in the Arcachon Bay. Indeed, the decline of the seagrass has been shown to occur throughout the Bay, even in tidal flat areas where S. anglica has never been observed.

\section{Conclusion}

Using a specific methodology to disentangle ecosystem engineering effects from short-term biotic effects at different distances from Spartina anglica, we showed that the invasive cordgrass had strong negative ecosystem engineering effects on Zostera noltei likely through sediment trapping and sediment-accretion occurring mostly at short distances (within Spartina patches). S. anglica also increased sediment oxygenation, a short-term positive effect on environmental conditions for a terrestrial plant, but that did not affect Z. noltei, an aquatic species strongly adapted to anoxia. We also found significant negative ecosystem engineering effects and positive short-term biotic effects of the cordgrass on the seagrass at a distance up to two meters from the Spartina patches, likely due its ability to alter wave energy with its stiff stems. However, these effects were much weaker than the short-distance effects and neutralized each other outside the Spartina patches, which allows us to conclude that the cordgrass weakly contributed to the regional decline of the seagrass documented throughout the Arcachon Bay. However, this does not preclude that on the long-term the coalescence of all Spartina patches on a tidal flat might transform this low intertidal habitat in a continuous salt marsh from which Z. noltei will be excluded. To complement this study and assess the role of the inter-annual variability in abiotic conditions, it would be appropriate to perform further experiments including measurements of nutrient and light availability for the Zostera transplants. Our results are crucial for stakeholders strongly involved in the control of the invasive, in particular through mechanical removal of the plants. Although these actions 
include a root removal of the invasive, they are very unlikely to limit the long-term invasion of the species due to the legacy effects on sediment elevation and oxygenation, which will remain in absence of sediment removal. Indeed, the new recruits of the cordgrass will find in these strongly modified habitats more suitable environmental conditions than before the invasion, thus, increasing the probability of further invasion.

\section{Acknowledgements}

The authors thank Guillaume Detandt for field assistance with dGPS measurements.

This work was financially supported by the UMR EPOC ("Innovative project" grant) and the French National Agency (ANR) in the frame of the Investments for the future Program, within the Cluster of Excellence COTE (ANR-10-LABX-45). B. Proença got PhD funding from the University of Bordeaux.

\section{Literature Cited}

Ainouche M, Chelaifa H, Ferreira J, Bellot S, Ainouche A, Salmon A (2012) Polyploid evolution in Spartina: dealing with highly redundant hybrid genomes. In: Polyploidy and Genome Evolution. Soltis PS, Soltis DE. Springer, New York, NY, p 255-244

Ainouche M, Fortune PM, Salmon A, Parisod C, Grandbastien M-A, Fukunaga K, Ricou M, Misset M-T (2009) Hybridization, polyploidy and invasion: lessons from Spartina (Poaceae). Biol Invasions 11:1159. 
Akaike H (1973) Information theory and an extension of the maximum likelihood principle. In: Proceedings of the Second International Symposium on Information theory. B.N. Petrov and S. Caski editors, Akademiai Kaido, Budapest, Hungary, p 267-281

Altieri AH, Wesenbeeck BK van, Bertness MD, Silliman BR (2010) Facilitation cascade drives positive relationship between native biodiversity and invasion success. Ecology 91:1269-1275

Armas C, Ordiales R, Pugnaire FI (2004) Measuring Plant Interactions: A new comparative index. Ecology 85:2682-2686

Auby I, Labourg P-J (1996) Seasonal dynamics of Zostera noltii hornem. in the Bay of Arcachon (France). Journal of Sea Research 35:269-277

Balke T, Klaassen PC, Garbutt A, Wal D van der, Herman PMJ, Bouma TJ (2012) Conditional outcome of ecosystem engineering: A case study on tussocks of the salt marsh pioneer Spartina anglica. Geomorphology 153-154:232-238

Bando, K. J. 2006. The Roles of Competition and Disturbance in a Marine Invasion. Biological Invasions 8:755-763.

Baumel A, Ainouche ML, Levasseur JE (2001) Molecular investigations in populations of Spartina anglica C.E. Hubbard (Poaceae) invading coastal Brittany (France). Molecular Ecology 10:1689-1701

Beest M te, Le Roux JJ, Richardson DM, Brysting AK, Suda J, Kubesová M, Pysek P (2012) The more the better? The role of polyploidy in facilitating plant invasions. Ann Bot 109:19-45

Bertness MD, Ewanchuk PJ (2002) Latitudinal and climate-driven variation in the strength and nature of biological interactions in New England salt marshes. Oecologia $132: 392-401$ 
Boudouresque CF, Bernard G, Pergent G, Shili A, Verlaque M (2009) Regression of Mediterranean seagrasses caused by natural processes and anthropogenic disturbances and stress: a critical review. Botanica Marina 52:395-418

Bouma T (2009) Comparing biodiversity effects among ecosystem engineers of contrasting strength: macrofauna diversity in Zostera noltii and spartina anglica vegetations. Helgol Mar Res:3-18

Bouma TJ, De Vries MB, Low E, Peralta G, Tánczos IC, Koppel J van de, Herman PMJ (2005) Trade-Offs Related to Ecosystem Engineering: A Case Study on Stiffness of Emerging Macrophytes. Ecology 86:2187-2199

Bouma TJ, Duren LA van, Temmerman S, Claverie T, Blanco-Garcia A, Ysebaert T, Herman PMJ (2007) Spatial flow and sedimentation patterns within patches of epibenthic structures: Combining field, flume and modelling experiments. Continental Shelf Research 27:1020-1045

Branco, J, Pedro S, Alves AS, Ribeiro C, Materatski P, Pires R, Caçador I, Adão H. (2017) Natural recovery of Zostera noltii seagrass beds and benthic nematode assemblage responses to physical disturbance caused by traditional harvesting activities. Journal of Experimental Marine Biology and Ecology.

Bruno JF, Stachowicz JJ, Bertness MD (2003) Inclusion of facilitation into ecological theory. Trends in Ecology \& Evolution 18:119-125

Callaway RM, King L (1996) Temperature-driven variation in substrate oxygenation and the balance of competition and facilitation. Ecology 77:1189-1195

Castellanos EM, Figueroa ME, Davy AJ (1994) Nucleation and facilitation in saltmarsh succession: interactions between Spartina maritima and Arthrocnemum perenne. Journal of Ecology 82:239-248 
Cognat M, Ganthy F, Auby I, Barraquand F, Rigouin L, Sottolichio A (2018) Environmental factors controlling biomass development of seagrass meadows of Zostera noltei after a drastic decline (Arcachon Bay, France). Journal of Sea Research 140: 87-104

Crooks JA (2002) Characterizing ecosystem-level consequences of biological invasions: the role of ecosystem engineers. Oikos 97:153-166

Den Hartog C, Polderman PJG (1975) Changes in the seagrass populations of the Dutch Waddenzee. Aquatic Botany 1:141-147.

Dostál P, Müllerová J, Pyšek P, Pergl J, Klinerová T (2013) The impact of an invasive plant changes over time. Ecology Letters 16:1277-1284

Duarte CM (2002) The future of seagrass meadows. Environmental Conservation 29:192-206

Folmer EO, Beusekom JEE van, Dolch T, Gräwe U, Katwijk MM van, Kolbe K, Philippart CJM (2016) Consensus forecasting of intertidal seagrass habitat in the Wadden Sea. J Appl Ecol 53:1800-1813

Ganthy F, Sottolichio A, Verney R (2013) Seasonal modification of tidal flat sediment dynamics by seagrass meadows of Zostera noltii (Bassin d'Arcachon, France). Journal of Marine Systems 109-110: S233-S240

Gribben, P. E., J. E. Byers, M. Clements, L. A. McKenzie, P. D. Steinberg, and J. T. Wright. 2009. Behavioural interactions between ecosystem engineers control community species richness. Ecology Letters 12:1127-1136.

Hacker SD, Bertness MD (1999) Experimental evidence for factors maintaining plant species diversity in a New England salt marsh. Ecology 80:2064-2073

Hacker SD, Heimer D, Hellquist CE, Reeder TG, Reeves B, Riordan TJ, Dethier MN (2001) A marine plant (Spartina anglica) invades widely varying habitats: Potential mechanisms of invasion and control. Biological Invasions 3:211-217 
Heide T van der, Bouma TJ, Nes EH van, Koppel J van de, Scheffer M, Roelofs JGM, Katwijk MM van, Smolders AJP (2010) Spatial self-organized patterning in seagrasses along a depth gradient of an intertidal ecosystem. Ecology 91:362-369

Kim J-H, Kim SH, Kim YK, Park J-I, Lee K-S (2016) Growth dynamics of the seagrass Zostera japonica at its upper and lower distributional limits in the intertidal zone. Estuarine, Coastal and Shelf Science 175:1-9

Lankau RA, Nuzzo V, Spyreas G, Davis AS (2009) Evolutionary limits ameliorate the negative impact of an invasive plant. PNAS 106:15362-15367

Laporte-Cru J, Werno J (1989) Spartina X Townsendii groves dans le Bassin d'Arcachon. Bulletins de la Société Linnéenne de Bordeaux 17:7-12 (in French).

Larkum AWD, Drew EA, Ralph PJ (2006) Photosynthesis and metabolism in seagrasses at the cellular level. In: Seagrasses: Biology, ecology and conservation. Springer Le Nindre YM, Levasseur JE, Benhammouda S, Cottet M, Lafon T (2004) Etude pour le maintien de l'équilibre bio-sédimentaire des plages du Nord-Est dans le Bassin d'Arcachon. Rapport BRGM/RP-53282-FR 101 p., 60 fig., 15 tabl., 6 ann (in French).

Lefcheck JS, Wilcox DJ, Murphy RR, Marion SR, Orth RJ (2017) Multiple stressors threaten the imperilled coastal foundation species eelgrass (Zostera marina) in Chesapeake Bay, USA. Glob Change Biol 23:3474-3483

Marba N, Cebrian J, Enriquez S, Duarte CM (1996) Growth patterns of Western Mediterranean seagrasses: species-specific responses to seasonal forcing. Marine Ecology Progress Series 133:203-215

Massa SI, Arnaud-Haond S, Pearson GA, Serrão EA (2009) Temperature tolerance and survival of intertidal populations of the seagrass Zostera noltii (Hornemann) in Southern Europe (Ria Formosa, Portugal). Hydrobiologia 619:195-201 
Michalet R (2006) Is facilitation in arid environments the result of direct or complex interactions? New Phytologist 169:3-6

Michalet R, Brooker RW, Lortie CJ, Maalouf J-P, Pugnaire FI (2015) Disentangling direct and indirect effects of a legume shrub on its understorey community. Oikos 124:12511262

Michalet R, Maalouf J-P, Hayek PA (2017) Direct litter interference and indirect soil competitive effects of two contrasting phenotypes of a spiny legume shrub drive the forb composition of an oromediterranean community. Oikos 126:1090-1100

Mitchell CE, Agrawal AA, Bever JD, Gilbert GS, Hufbauer RA, Klironomos JN, Maron JL, Morris WF, Parker IM, Power AG, Seabloom EW, Torchin ME, Vázquez DP (2006) Biotic interactions and plant invasions. Ecology Letters 9:726-740

Noumi Z, Chaieb M, Bagousse-Pinguet YL, Michalet R (2016) The relative contribution of short-term versus long-term effects in shrub-understory species interactions under arid conditions. Oecologia 180:529-542

Noumi Z, Chaieb M, Michalet R, Touzard B (2015) Limitations to the use of facilitation as a restoration tool in arid grazed savanna: a case study (R Ohlemuller, Ed.). Applied Vegetation Science 18:391-401

Orth RJ, Carruthers TJB, Dennison WC, Duarte CM, Fourqurean JW, Heck KL, Hughes AR, Kendrick GA, Kenworthy WJ, Olyarnik S, Short FT, Waycott M, Williams SL (2006) A Global Crisis for Seagrass Ecosystems. BioScience 56:987-996

Paul M, Gillis LG (2015) Let it flow: how does an underlying current affect wave propagation over a natural seagrass meadow? Mar Ecol Prog Ser 523:57-70

Planty-Tabacchi A-M, Tabacchi E, Naiman RJ, Deferrari C, Decamps H (1996) Invasibility of Species-Rich Communities in Riparian Zones. Conservation Biology 10:598-607 
Plus M, Dalloyau S, Trut G, Auby I, Montaudouin X de, Éric, Noël C, Viala C (2010) Longterm evolution (1988-2008) of Zostera spp. meadows in Arcachon Bay (Bay of Biscay). Estuarine, Coastal and Shelf Science 87:357-366

Pyšek P, Hulme PE (2005) Spatio-temporal dynamics of plant invasions: Linking pattern to process. Ecoscience 12:302-315

R Development Core Team (2013) R: A language and environment for statistical computing. R Foundation for Statistical Computing, Vienna, Austria

Raybould AF, Gray AJ, Lawrence MJ, Marshall DF (1991) The evolution of Spartina anglica C.E. Hubbard (Gramineae): origin and genetic variability. Biological Journal of the Linnean Society 43:111-126

Rietkerk M, Koppel J van de (2008) Regular pattern formation in real ecosystems. Trends in Ecology \& Evolution 23:169-175Saccone P, Brun J-J, Michalet R (2010) Challenging growth-survival trade-off: a key for Acer negundo invasion in European floodplains? - Canadian Journal of Forest Research. Canadian Journal Forest Research 40:18791886

Saccone P, Pagès J-P, Girel J, Brun J-J, Michalet R (2010) Acer negundo invasion along a successional gradient: early direct facilitation by native pioneers and late indirect facilitation by conspecifics. New Phytologist 187:831-842

Sánchez JM, SanLeon DG, Izco J (2001) Primary colonisation of mudflat estuaries by Spartina maritima (Curtis) Fernald in Northwest Spain: vegetation structure and sediment accretion. Aquatic Botany 69:15-25

Schöb C, Butterfield BJ, Pugnaire FI (2012) Foundation species influence trait-based community assembly. New Phytologist 196:824-834 
Seabloom EW, Ruggiero P, Hacker SD, Mull J, Zarnetske P (2013) Invasive grasses, climate change, and exposure to storm-wave overtopping in coastal dune ecosystems. Glob Change Biol 19:824-832

Shapiro, S. S. \& M. B. Wilk. 1965. An analysis of variance test for normality (completesamples).Biometrika52: 591-611. [181, 183]

Steinbauer MJ, Beierkuhnlein C, Arfin Khan MAS, Harter DEV, Irl SDH, Jentsch A, Schweiger AH, Svenning J-C, Dengler J (2016) How to differentiate facilitation and environmentally driven co-existence (M Palmer, Ed.). Journal of Vegetation Science 27:1071-1079

Strayer DL (2012) Eight questions about invasions and ecosystem functioning (H Hillebrand, Ed.). Ecology Letters 15:1199-1210

Strayer DL, Eviner VT, Jeschke JM, Pace ML (2006) Understanding the long-term effects of species invasions. Trends in Ecology \& Evolution 21:645-651

Strong D, Ayres DR (2013) Ecological and evolutionary misadventures of Spartina. Annual Review of Ecology, Evolution, and Systematics 44:389-410

Suykerbuyk W, Bouma TJ, Govers LL, Giesen K, Jong DJ de, Herman P, Hendriks J, Katwijk MM van (2016) Surviving in changing seascapes: sediment dynamics as bottleneck for long-term seagrass presence. Ecosystems 19:296-310

Suykerbuyk W, Govers LL, Bouma TJ, Giesen WBJT, Jong DJ de, Voort R van de, Giesen K, Giesen PT, Katwijk MM van (2016) Unpredictability in seagrass restoration: analysing the role of positive feedback and environmental stress on Zostera noltii transplants. J Appl Ecol 53:774-784

Theoharides KA, Dukes JS (2007) Plant invasion across space and time: factors affecting nonindigenous species success during four stages of invasion. New Phytol 176:256273 
Treier UA, Broennimann O, Normand S, Guisan A, Schaffner U, Steinger T, Müller-Schärer H (2009) Shift in cytotype frequency and niche space in the invasive plant Centaurea maculosa. Ecology 90:1366-1377

Vilà M, Espinar JL, Hejda M, Hulme PE, Jarošík V, Maron JL, Pergl J, Schaffner U, Sun Y, Pyšek P (2011) Ecological impacts of invasive alien plants: a meta-analysis of their effects on species, communities and ecosystems. Ecology Letters 14:702-708

Vitousek PM (1990) Biological Invasions and Ecosystem Processes: Towards an Integration of Population Biology and Ecosystem Studies. In: Ecosystem Management. Springer, New York, NY, p 183-191

Vu HD, Wieski K, Pennings SC (2017) Ecosystem engineers drive creek formation in salt marshes. Ecology 98:162-174

Waycott M, Duarte CM, Carruthers TJB, Orth RJ, Dennison WC, Olyarnik S, Calladine A, Fourqurean JW, Heck KL, Hughes AR, Kendrick GA, Kenworthy WJ, Short FT, Williams SL (2009) Accelerating loss of seagrasses across the globe threatens coastal ecosystems. PNAS 106:12377-12381

Zarnetske PL, Hacker SD, Seabloom EW, Ruggiero P, Killian JR, Maddux TB, Cox D (2012) Biophysical feedback mediates effects of invasive grasses on coastal dune shape. Ecology 93:1439-1450 


\section{Tables}

Table 1. Neighbouring treatments used for calculating the three interaction indices (RII) for the vegetation, soil and net Spartina effects on Zostera noltei performances. SA: intactSpartina anglica treatment, SAC: cut-Spartina anglica treatment and control: bare sediment treatment.

With neighbour

Without neighbour

\begin{tabular}{l|c|}
$\boldsymbol{R I I}_{\text {vegetation }}$ & $\begin{array}{c}\text { Abundance of Z. noltei in SA } \\
\boldsymbol{R I I}_{\text {soil }}\end{array}$ \\
$\boldsymbol{R I I}_{\text {Spartina }}$ & Abundance of Z. noltei in SAC \\
& Abundance of Z. noltei in SA
\end{tabular}

Abundance of Z. noltei in SAC

Abundance of $Z$. noltei in control

Abundance of Z. noltei in control 
Table 2. Results of the mixed linear models on the effects of the transect (or method), position (and position ${ }^{2}$ ) and their interactions on the logarithm of final abundance of Zostera noltei (left) and Relative Interaction Index (right). Significant results are indicated in bold. Pvalue significance thresholds: *, $\mathrm{p}<0.05 ; * *, \mathrm{p}<0.01 ; * * *, \mathrm{p}<0.001$

\section{$\log ($ final abundance+1)}

RII

Effects

\begin{tabular}{llllll}
\hline $\mathrm{F}$ & $\mathrm{P}$ & Variable & $d f$ & $\mathrm{~F}$ & $\mathrm{p}$
\end{tabular}

transect

$2 \quad 12.96$

$<0.001$

method

$\begin{array}{lll}2 & 23.59 & <\mathbf{0 . 0 0 1}\end{array}$

Position

$1 \quad 1.31$

0.256

position

14.14

0.045

position $^{2}$

$1 \quad 19.55$

$<0.001$

position $^{2}$

111.46

0.001

transect $x$ pos.

$2 \quad 0.77$

0.466

method $x$ pos. $\quad 2 \quad 0.59$

0.557

transect $x$ pos. $^{2} \quad 2 \quad 5.42$

0.006

method $x$ pos. ${ }^{2}$

$2 \quad 2.73$

0.071

Residuals 
Table 3. Results of the ANOVA on the effects of the transect, position (and position ${ }^{2}$ ) treatments and their interactions on altimetry, redox potential (Eh) and relative fine sediment content. Significant results are indicated in bold. P-value significance thresholds: ${ }^{*}, \mathrm{p}<0.05$; $* *, \mathrm{p}<0.01 ; * * *, \mathrm{p}<0.001$.

\begin{tabular}{|c|c|c|c|c|c|c|c|c|c|}
\hline \multirow[b]{2}{*}{ Effects } & \multirow[b]{2}{*}{$d f$} & Alti & netry & \multicolumn{3}{|c|}{ Eh } & & \multicolumn{2}{|c|}{$\begin{array}{c}\text { Relative fine } \\
\text { sediment content }\end{array}$} \\
\hline & & $\mathrm{F}$ & $\mathrm{p}$ & $d f$ & $\mathrm{~F}$ & $\mathrm{p}$ & $d f$ & $\mathrm{~F}$ & $\mathrm{p}$ \\
\hline transect & 2 & 4.42 & 0.014 & 2 & 2.16 & 0.121 & 2 & 0.36 & 0.670 \\
\hline position & 1 & 0.01 & 0.916 & 1 & 0.11 & 0.737 & 1 & 10.81 & 0.001 \\
\hline position $^{2}$ & 1 & 8.17 & 0.005 & 1 & 1.62 & 0.206 & 1 & 1.05 & 0.309 \\
\hline transect $\times$ pos. & 2 & 0.40 & 0.670 & 2 & 2.96 & 0.056 & 2 & 2.66 & 0.074 \\
\hline transect $x$ pos. ${ }^{2}$ & 2 & 3.95 & 0.022 & 2 & 0.34 & 0.713 & 2 & 1.23 & 0.297 \\
\hline Residuals & 103 & & & 103 & & & 103 & & \\
\hline
\end{tabular}




\section{Figures}

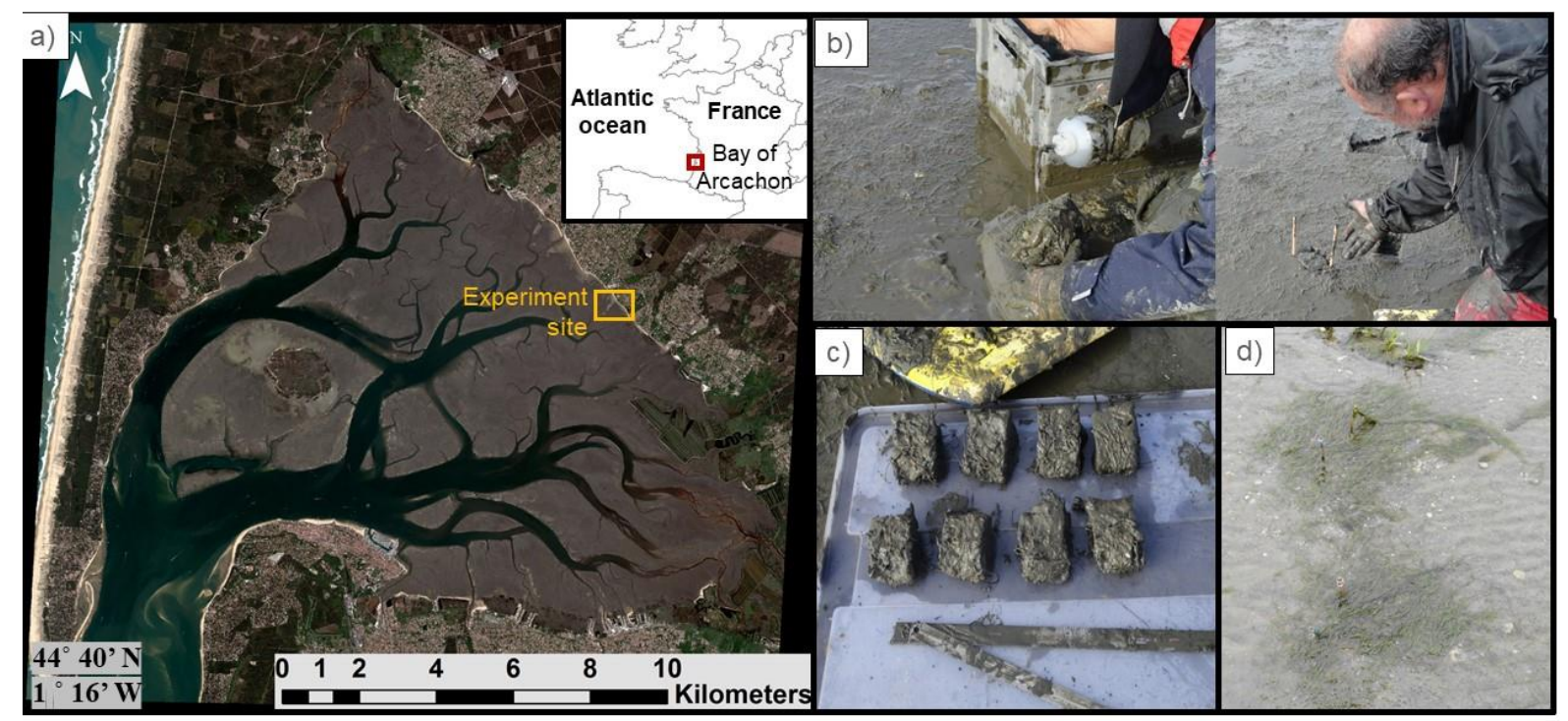

Figure 1. a) Study site location. b) Implementation of experiment: counting of Zostera noltei individuals in a transplant plot (figure on the left) and placement of transplant plot in transect, with the wooden sticks delimiting two diagonal extremes of the transplant plot at $\mathrm{T}_{\mathrm{i}}$ (figure on the right). c) Transplant plots to be implemented in a transect. The plots shown in the figure are representative of the development stage of the Zostera noltei individuals at the beginning of the experiment. d) Two positions within a transect, outside the Spartina patch at $\mathrm{T}_{\mathrm{f}}$. 


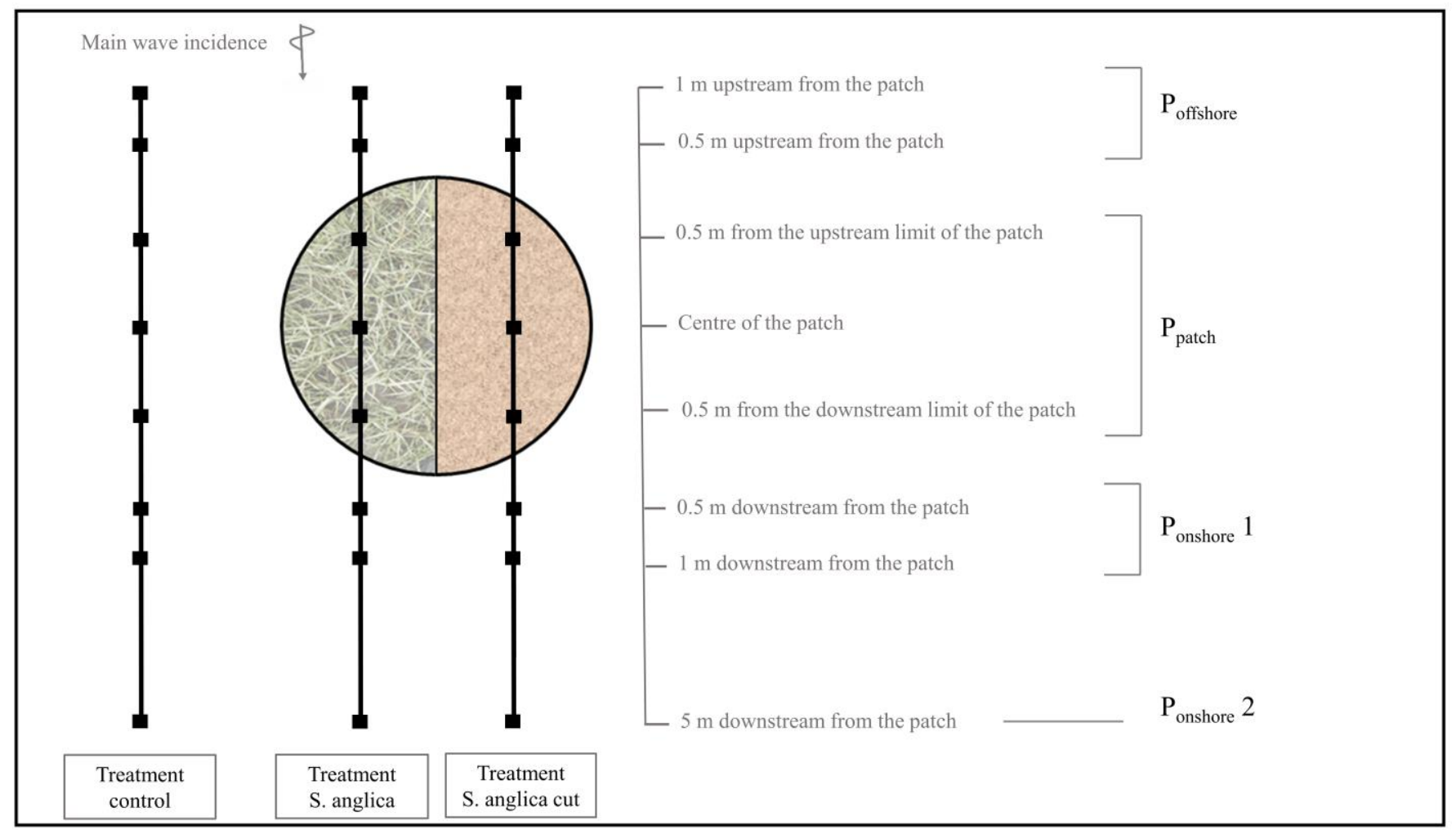

Figure 2. Design of the experiment. Black squares represent the positions of the Zostera noltei transplants along transects for each treatment. Control treatments were implemented on mudflat in the direct vicinity of Spartina patches (approximately 10 meters), S. anglica treatment corresponds to transects crossing the intact half of Spartina patches and S. anglica cut treatment corresponds to transects crossing the cut half of Spartina patches where aerial vegetation was cut. After a first statistical analysis, performance of transplant positions showing no significant differences between them were pooled and reduced to four main positions: Position offshore $\left(\mathrm{P}_{\text {offshore }}\right)$, Position inside patch $\left(\mathrm{P}_{\mathrm{patch}}\right), 1^{\text {st }}$ Position onshore ( $\left.\mathrm{P}_{\text {onshore }} 1\right)$ and $2^{\text {nd }}$ Position onshore $\left(\mathrm{P}_{\text {onshore }} 2\right)$. 


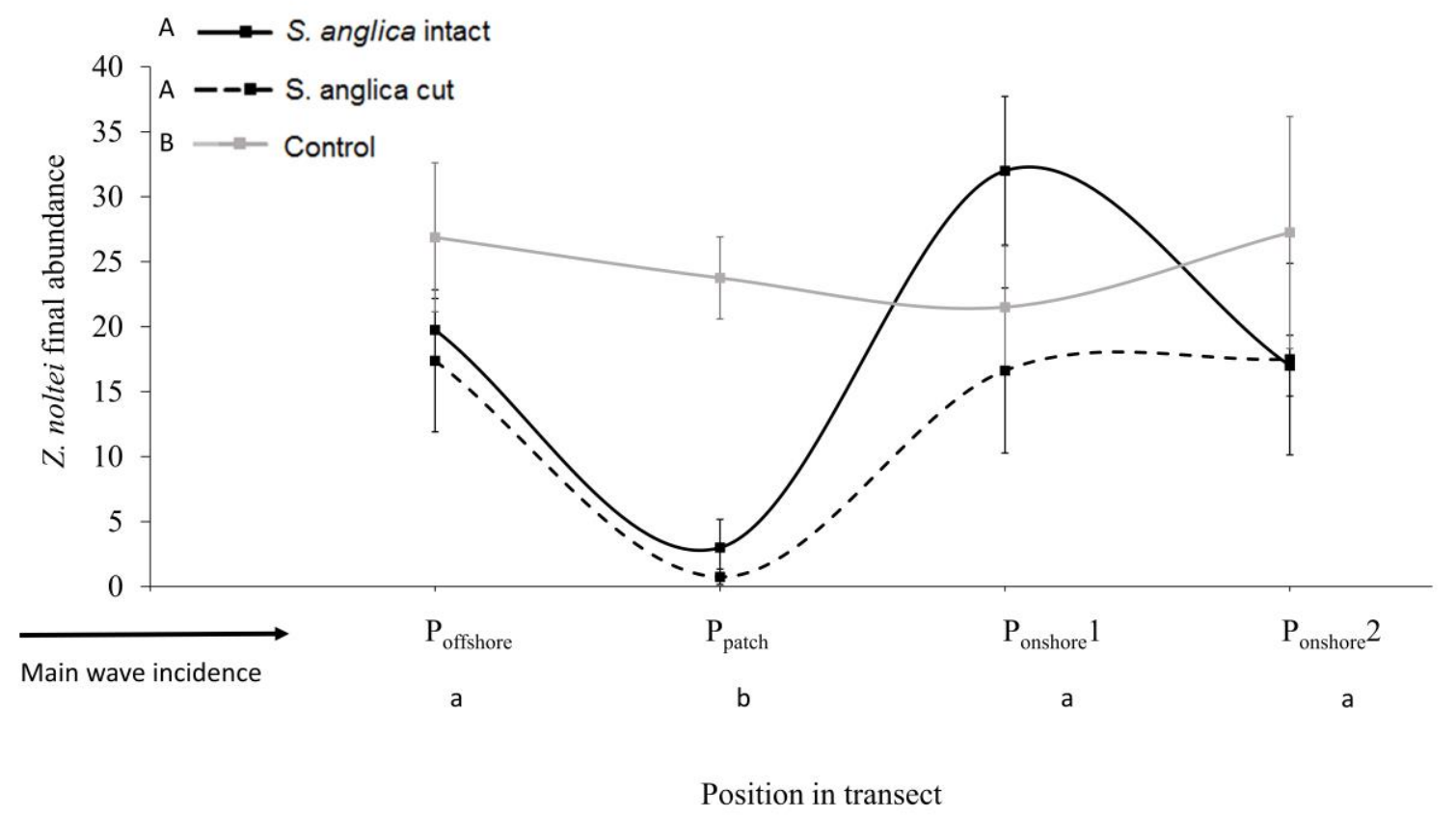

Figure 3. Mean ( \pm SE) Zostera noltei final number of individuals per transplant plot at four positions along intact-Spartina transect (SA) - solid black line, along cut-Spartina transect (SAC) - dashed black line and along control transect (bare sediment) - grey solid line. Positions along transect: within $1 \mathrm{~m}$ on the offshore side of the patch ( $\mathrm{P}_{\text {offshore }}$ ), inside the patch $\left(\mathrm{P}_{\mathrm{patch}}\right)$, within $1 \mathrm{~m}$ on the onshore side of the patch $\left(\mathrm{P}_{\text {onshore } 1}\right)$ and $5 \mathrm{~m}$ away from the patch ( $\left.\mathrm{P}_{\text {onshore }}\right)$. Upper-case letters are the results of the Tukey test for the transect effect and lower-case letters are the results of the Tukey test for the position effect (with significance at $\mathrm{p}<0.05)$. 


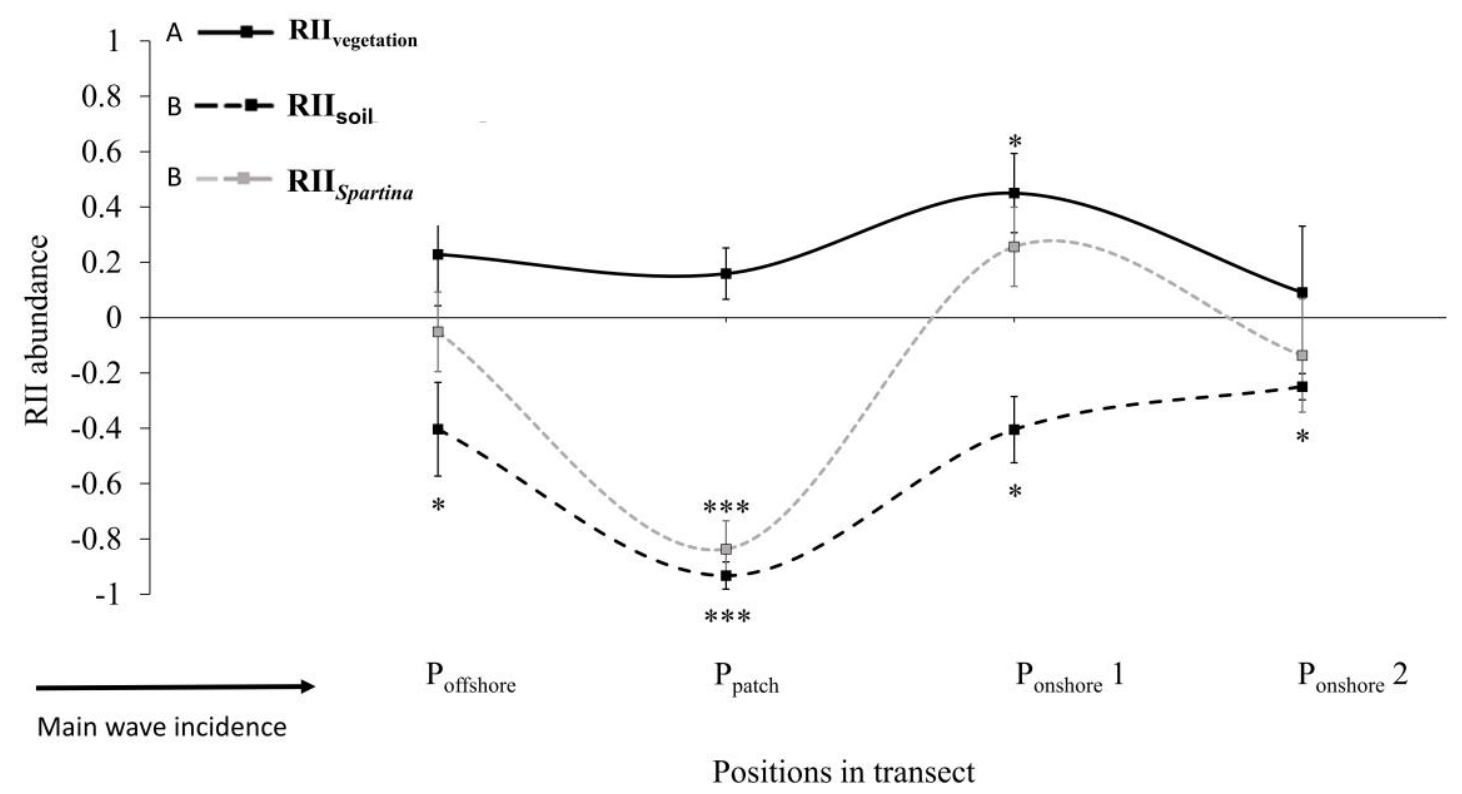

Figure 4. Mean ( \pm SE) Relative Interaction Intensity (RII) index for final Zostera noltei abundance per transplant plot at four positions along transects. See Table 2 for the ecological

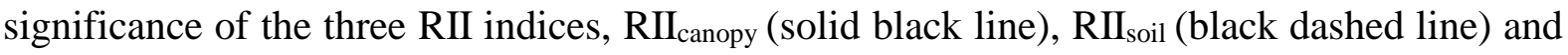
RII $_{\text {Spartina }}$ (grey dashed line). Positions along transect: within $1 \mathrm{~m}$ on the offshore side of the patch $\left(\mathrm{P}_{\text {offshore }}\right)$, inside the patch $\left(\mathrm{P}_{\text {patch }}\right)$, within $1 \mathrm{~m}$ on the onshore side of the patch $\left(\mathrm{P}_{\text {onshore } 1}\right)$ and $5 \mathrm{~m}$ away from the patch $\left(\mathrm{P}_{\text {onshore } 2}\right)$. Asterisks show the results of the T-tests: $*<0.05$, $* *$ $<0.01$ and $* * *<0.001$. Upper-case letters indicate the results of the Tukey test for the method effect (with significance at $\mathrm{p}<0.05$ ). 


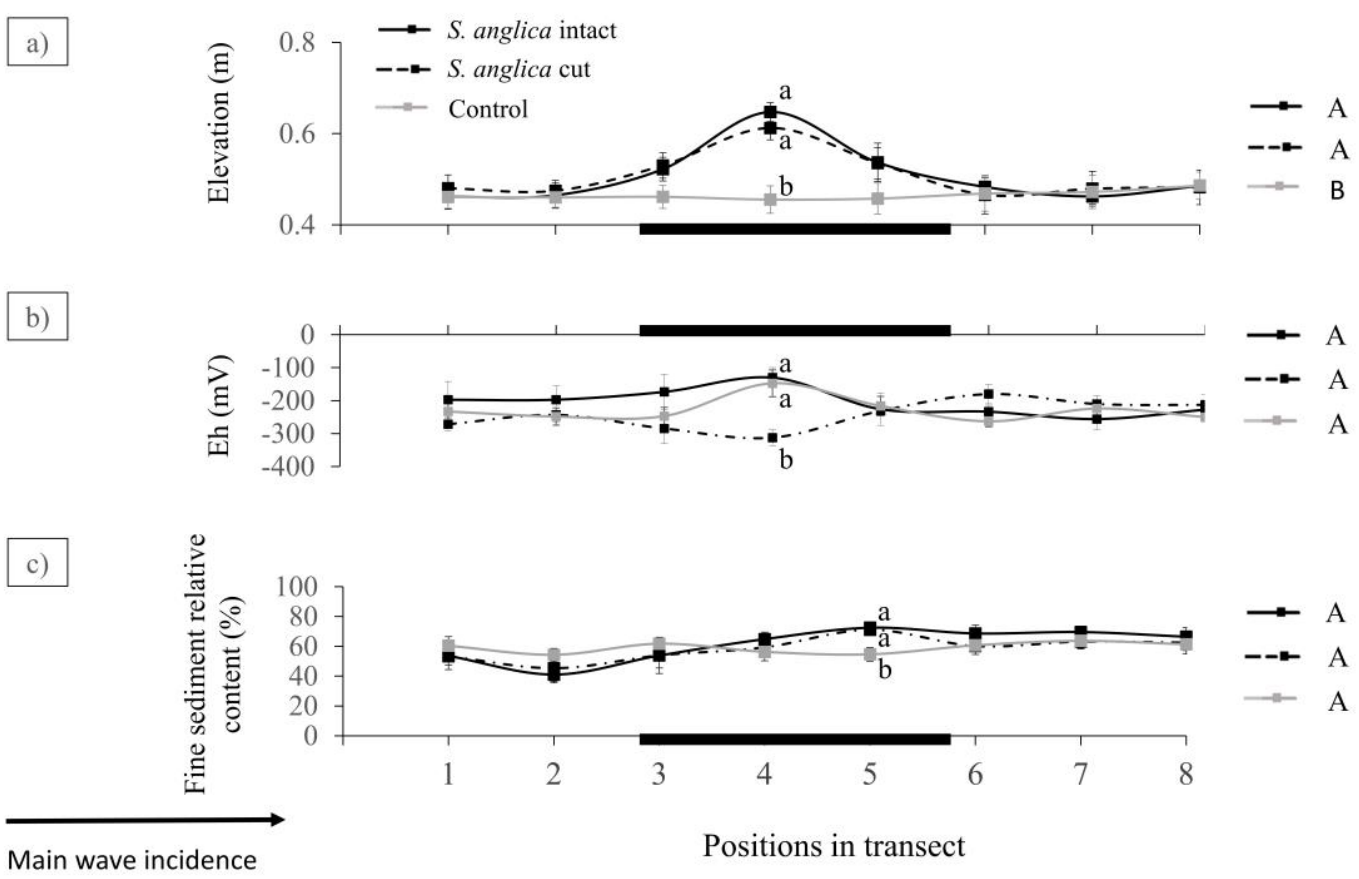

Figure 5. Mean $( \pm \mathrm{SE})$ a) elevation of transect positions, b) Soil redox potential (Eh) and c) Relative fine sediment content, for the three transect types, intact-Spartina (SA), cut-Spartina (SAC) and control transect (bare sediment). Transect positions 1 to 8 are from upstream to downstream the Spartina patches and correspond precisely to $1 \mathrm{~m}(1)$ and $0.5 \mathrm{~m}(2)$ upstream from the patch border, $0.5 \mathrm{~m}$ (3) within the patch on the upstream side, centre of the patch (4), $0.5 \mathrm{~m}$ within the patch from the downstream border (6), $1 \mathrm{~m} \mathrm{(7)}$ and $5 \mathrm{~m}(8)$ downstream from the patch, respectively. In both graphics, the solid black line between points 3 and 5 shows the position of the Spartina patch within the transect. Upper-case letters indicate the results of the Tukey test for the transect treatment (with significance at $p<0.05$ ). Small case letters indicate the results for Tukey test for the particular positions where the transect treatment is significant (with significance at $\mathrm{p}<0.05$ ), namely P4 for altimetry and Eh and P5 for fine sediment content. 